\title{
Radiojornalismo comunitário em mídias sociais e microblogs: circulação de conteúdos publicados no portal RadioTube ${ }^{\mathrm{i}}$
}

\author{
MARCELO KISCHINHEVSKY \\ Universidade do Estado do Rio de Janeiro - marcelokisch@gmail.com \\ Professor do Departamento de Jornalismo e do Programa em Pós-Graduação \\ em Comunicação da Faculdade de Comunicação Social da UERJ \\ onde coordena o Laboratório de Áudio (AudioLab). É bacharel em Comunicação, \\ habilitação Jornalismo, com Mestrado e Doutorado em Comunicação e Cultura \\ pela Escola de Comunicação da Universidade Federal do Rio de Janeiro (ECO/UFRJ).
}

\begin{abstract}
Resumo
O presente artigo busca investigar de que modo a circulação de conteúdos radiojornalísticos se reconfigura com a consolidação de plataformas digitais de comunicação, como mídias sociais e serviços de microblogging, que ajudam a construir redes sociais online e offline. Parte-se da premissa de que estas plataformas potencializam não só o alcance de rádios comerciais, mas também da radiodifusão comunitária. Serão analisadas particularmente as estratégias para distribuição e circulação de arquivos de áudio digital no portal colaborativo RadioTube, que conta com uma rede de mais de 1,4 mil emissoras comunitárias, comerciais e web de todas as regiões do Brasil.
\end{abstract}

\section{Palavras-chave}

Rádio. Jornalismo. Mídias Sociais.

\begin{abstract}
This paper seeks to investigate how radio journalism contents' circulation reconfigures itself in a period of consolidation of digital communications' platforms, such as social media and microblogging services, which support the construction of online and offline social networks. It starts with the premise that these platforms leverage not only commercial radios range but also community broadcasting. Particularly, it will analyze digital audio distribution and circulation strategies at the Brazilian collaborative portal Radiotube, that comprehends a network of over 1,400 communitary, commercial, and web radios from all over the country.
\end{abstract}

Keywords

Radio. Journalism. Social Media

Artigo recebido em 10/11/2011

Aprovado em 01/03/2012 


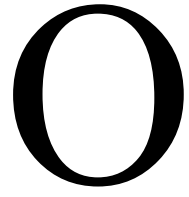

apresentador pausa a playlist com um clique na mesa de som, faz um breve comentário jocoso sobre a música recém-executada de uma artista pop presença constante no noticiário de celebridades, por seu comportamento fora dos palcos -, dispara uma vinheta e inicia, em seguida, a leitura de mensagens de ouvintes, selecionadas no serviço de microblogging Twitter antes de chamar um quadro fixo, em que, com humor de gosto duvidoso, busca reconciliar jovens casais. Antes, durante e depois do programa, o comunicador, com apoio de uma produtora, alimenta seu próprio perfil no Twitter e no site de relacionamentos Facebook, divulgando promoções, provocando a interação com e entre os ouvintes, construindo, enfim, uma rede social em torno dos conteúdos radiofônicos veiculados na emissora, uma das líderes em audiência do segmento jovem em Frequência Modulada (FM) no Rio de Janeiro.

Cada vez mais, esta é a rotina de jornalistas e radialistas, que se desdobram nas funções de apresentadores, produtores e/ou repórteres, publicando na internet links para programas, entrevistas, comentários, reportagens, podcasts sobre os mais diversos temas e dos mais variados formatos, tanto nas FMs musicais quanto nas emissoras informativas. O rádio encontra-se hoje expandido. Transborda para mídias sociais e microblogs, que potencializam seu alcance e a circulação de seus conteúdos, muitas vezes substituindo a entrada no ar de ouvintes ao vivo por telefone e redesenhando as formas de apropriação pela audiência.

Mais do que isso, o rádio hoje não é mais privilégio apenas de concessionários em geral, no Brasil, empresários amigos do poder - autorizados a operar em FM e Ondas Médias (AM). Diversos atores sociais, antes privados de acesso aos meios de comunicação, conquistam condições materiais de criação, produção e distribuição de conteúdos radiofônicos, graças ao avanço das plataformas digitais na internet. E, neste cenário de luta para se fazer ouvir, o radiojornalismo emerge como uma opção, uma operação de custo relativamente baixo e grande alcance social. O rádio está presente em 87,9\% dos lares brasileiros, de acordo com a Pesquisa Nacional por Amostra de Domicílios (Pnad), do Instituto Brasileiro de Geografia e Estatística (IBGE), de 2009, percentual que se mantém estável ao longo de toda a década ${ }^{i i}$. Além disso, o meio é 
consumido cada vez mais em suportes como o telefone celular e o computador pessoal (FERRARETTO; KISCHINHEVSKY, 2010), engendrando novas práticas interacionais e ampliando suas potencialidades comunicacionais, a ponto de ser rebatizado por alguns autores como "rádio hipermidiático" (LOPEZ, 2010) ou "ciberradio" (CEBRIÁN HERREROS, 2008).

Não se está falando aqui, é importante ressaltar, da perspectiva utópica de pesquisadores que fazem a apologia das novas tecnologias da informação e da comunicação e enxergam uma revolução no processo comunicacional, com a suposta liberação do polo emissor. É certo que a internet implica crescente desintermediação, oferecendo ferramentas para comunicação direta muitos-muitos, numa lógica distinta das transmissões um-muitos, do padrão broadcasting. A consolidação da rede mundial de computadores, contudo, traz ao mesmo tempo uma reintermediação, franqueando acesso ao mercado, não apenas a novos atores sociais, mas também fortalecendo novos intermediários (BUSTAMANTE et al., 2003, p. 333-335).

No caso do rádio, os novos intermediários, responsáveis pela distribuição e pela circulação dos conteúdos, são os mais diversos. Abrangem desde os portais que concentram web rádios e podcasts, operando como as antigas listas telefônicas, motores de busca e sites de emissoras AM/FM até mídias sociais, comunidades on-line, fóruns e serviços de microblogging, que potencializam o alcance de reportagens radiofônicas, notícias, boletins, comentários, entrevistas e programas, inclusive aqueles produzidos à margem da indústria da radiodifusão sonora, por pessoas físicas, militantes de movimentos sociais ou outras entidades - sindicatos, universidades, organizações nãogovernamentais, empresas privadas sem vínculos prévios com a radiodifusão etc.

O presente artigo, resultado de pesquisas desenvolvidas nos últimos dois anos no AudioLab da Faculdade de Comunicação Social da Universidade do Estado do Rio de Janeiro (FCS/UERJ), busca investigar as diversas formas de distribuição e de circulação de conteúdos radiofônicos via internet e em que medida estas estratégias oferecem alternativas comunicacionais, amplificando vozes que antes não podiam ser ouvidas (ou eram filtradas pelas emissoras comerciais e estatais) no dial. Para tanto, foi escolhido como estudo de caso o portal brasileiro RadioTube, projeto colaborativo mantido pela 
organização não-governamental Criar Brasil, que se apresenta como uma alternativa à radiodifusão comercial via internet e atende uma rede de mais de 1,4 mil emissoras - na maioria, comunitárias - de todo o Brasil.

Entende-se o RadioTube, neste trabalho, como exemplar de uma nova modalidade de radiofonia, uma mídia social de base radiofônica, ou simplesmente um serviço de rádio social, conceito que será desenvolvido mais adiante.

\title{
Circulação jornalística em mídias sociais e microblogs
}

Mídias sociais se tornaram um campo fértil para pesquisas em comunicação, suscitando as mais diversas abordagens. Analisar a formação de redes sociais on-line, contudo, representa um desafio teórico-metodológico, sobretudo quanto à construção de amostras em pesquisas empíricas.

\begin{abstract}
A internet é um universo de investigação particularmente difícil de recortar, em função de sua escala (seus componentes contam-se aos milhões e bilhões), heterogeneidade (grande variação entre as unidades e entre os contextos) e dinamismo (todos os elementos são permanentemente passíveis de alteração e a configuração do conjunto se modifica a cada momento). (FRAGOSO; RECUERO; AMARAL, 2011, p. 55).
\end{abstract}

Mas o que motiva a formação destas redes sociais? Raquel Recuero vê o capital social como chave para compreensão deste processo. Cotejando o conceito em Putnam, Bourdieu e Coleman, a autora vai entender capital social "como um conjunto de recursos de determinado grupo [...] que pode ser usufruído por todos os membros do grupo, ainda que individualmente, e que está baseado na reciprocidade" (RECUERO, 2009, p. 50). Este capital social não seria inato, mas relacional. Ou seja, seria construído nas interações entre os indivíduos.

$\mathrm{Na}$ perspectiva utópica dos primeiros estudos sobre cibercultura, a internet proporcionaria uma possibilidade de comunicação todos-todos, sem intermediários. As relações na rede, contudo, são claramente assimétricas, como evidenciam as análises de redes sociais (ou ARS), campo de estudos em expansão, que conjuga modelos matemáticos e métodos de pesquisa quantitativa e qualitativa. Numa rede, alguns integrantes assumem o papel de protagonistas, enquanto a grande maioria permanece como coadjuvante, interagindo muito pouco (ou nada) com os demais. 
As redes sociais on-line têm sido cada vez mais estudadas porque potencializam a distribuição e a circulação de informação e, ainda, propiciam o rastreamento desta difusão. Empreendendo uma revisão bibliográfica sobre o tema, na análise específica de circulação de mensagens via Twitter, Raquel Recuero e Gabriela Zago buscam compreender de que forma o serviço de microblogging gera valor. $\mathrm{Na}$ "economia do retweet" analisada pelas pesquisadoras, um pequeno número de participantes da rede assume o papel de divulgar e filtrar informações, gerando um benefício coletivo e, simultaneamente, angariando reputação e capacidade de influência. Os principais valores gerados pela prática de retweetariii seriam, portanto, a referencialidade, o acesso à informação, e a compressão do tempo, relacionada ao fator novidade - afinal, supõese que a informação retweetada seja nova, para gerar interesse dos demais integrantes da rede. Ou seja, o retweet tornou-se o motor do serviço, funcionando como moeda e como prática hierarquizante.

Quando alguém faz um RT, está repassando uma informação que acredita que sua rede ainda não tenha recebido. Está, portanto, provendo acesso a algo que considera relevante. Essa ação de filtragem coletiva mantém a informação circulando e a leva a lugares mais distantes na rede. Gera, portanto, um benefício público, coletivo, decorrente da estrutura da rede. Entretanto, como o retweet também possui referencialidade, ele também gera bens privados, pois a visibilidade dos atores que são retuítados pode gerar um número maior de seguidores, tipos diferentes de reputação e mesmo credibilidade. Enquanto esses valores são gerados pela difusão de informações que está construindo bens que são públicos, é apropriada privativamente pelos indivíduos. [...] Para acrescentar valor, muitos optam por fazer comentários pessoais, e mesmo incitar conversações. (RECUERO; ZAGO, 2011)

Infelizmente, ainda são raros os estudos acadêmicos sobre a circulação jornalística na internet, o que prejudica a "compreensão da dinâmica do jornalismo como um complexo de sistemas integrados", que abrange ainda a apuração, a produção e o financiamento (MACHADO, 2008). Ainda segundo Elias Machado, "a disseminação de informações no ciberespaço depende cada vez mais de sistemas dinâmicos, múltiplos e inteligentes de circulação, em contraposição aos sistemas estáticos e centralizados, adotados nos primeiros anos pelos ciberjornalistas" (idem, ibidem). 
O retweet é um exemplo de como a circulação de conteúdos via internet foi potencializada. Há quem defenda, até, a existência de uma nova subetapa do processo jornalístico, a recirculação, posterior às tradicionais - apuração, produção, circulação e consumo (ZAGO, 2011). Na recirculação, conforme proposto pela pesquisadora, o receptor (ou interagente) apropria-se de determinado conteúdo jornalístico e o faz circular novamente, em suas próprias palavras ou acrescentando comentários. Graças a programas que encurtam URLs, uma mensagem de 140 caracteres pode conter links para conteúdos em texto, áudio, vídeo, foto, amplificando seu alcance.

A reconfiguração do rádio, com seu desenvolvimento rumo às plataformas digitais, faz o meio desenvolver relações cada vez mais simbióticas com mídias sociais e serviços de microblogging. O áudio tem sido moeda importante para diversos portais, que vêm se constituindo como mídias sociais de base radiofônica, ou rádio social.

Outros trabalhos (HERSCHMANN; KISCHINHEVSKY, 2008, e KISCHINHEVSKY, 2011, respectivamente) trazem uma análise sobre estas novas modalidades de radiofonia constituídas pelo podcasting e pelas mídias sociais de base radiofônica. O podcasting, de recepção assíncrona, franqueia acesso permanente a conteúdos que antes se perderiam após a veiculação em ondas hertzianas e também fornece ferramentas baratas ou gratuitas para produção e distribuição de conteúdos em áudio por novos atores sociais - como universidades, movimentos sociais, organizações não-governamentais (ONGs) e pessoas físicas. O rádio social, por sua vez, potencializa a circulação de arquivos digitais de áudio, que vão sendo consumidos e redistribuídos por múltiplas redes on-line. As duas modalidades apresentam caráter claramente complementar. Um podcaster não pode abrir mão da visibilidade proporcionada pelas mídias sociais, e estas, em contrapartida, se alimentam deste fluxo de informações para que suas redes ganhem densidade.

O Twitter é apenas um dos serviços usados pelos radiodifusores, sejam eles institucionais ou individuais. A circulação radiojornalística via internet ganha impulso em diversos microblogs, mídias sociais e serviços de rádio social. Pessoas físicas, rádios comunitárias, grandes grupos de comunicação - todos buscam tornar os conteúdos que postam na internet cada vez mais passíveis de circulação, intercambiáveis. Quanto mais 
botões de compartilhamento disponíveis num destes serviços, maiores as chances de um áudio atingir grande público ouvinte.

\section{Rádio social, alternativa para emissoras comunitárias}

Um dos serviços considerados aqui como rádio social é o RadioTube, site colaborativo que tem como bordão "A cidadania por todas as ondas". Mantido pela ONG Criar Brasil - Centro de Imprensa, Assessoria e Rádio, reúne aficionados, ativistas de rádios comunitárias e organizações ligadas a movimentos sociais, com o objetivo de "formar uma rede social que produza conhecimento coletivo e informação cidadã"iv . O Criar Brasil é um desdobramento do Centro de Imprensa Alternativa (Cria), setor do Instituto Brasileiro de Análises Sociais e Econômicas (Ibase) concebido pelo sociólogo Herbert de Souza, o Betinho, nos anos 1990. Sua missão é "apoiar as organizações dos movimentos sociais através da produção, capacitação, assessoria e pesquisa radiofônica, visando a democratização da comunicação no Brasil”"

O projeto RadioTube - Rede de Cidadania evoluiu da Rede de Cidadania nas Ondas do Rádio, desenvolvida pelo Criar Brasil em 2007, com patrocínio da Petrobras, no âmbito do Programa Desenvolvimento \& Cidadania, e mobilizando uma rede de 635 emissoras de rádio de todo o país.

Em 2008, o portal entrou no ar, passando a oferecer conteúdos radiofônicos, como spots, entrevistas e programas radiojornalísticos, com ênfase em temas como comunicação democrática, saúde, educação, direitos humanos, direitos dos trabalhadores e das crianças e adolescentes, questões relacionadas a gênero e diversidade étnica. Membro da Associação Mundial de Rádios Comunitárias (Amarc), a Criar Brasil atua ainda como capacitadora da Amarc/Brasil, promovendo oficinas para jovens comunicadores de rádios comunitárias. A ONG conta com uma equipe de dez pessoas, entre radialistas, jornalistas e equipe de TI, fora os colaboradores, publicando em média 28 conteúdos por mês ao longo de 2011.

Oficinas de capacitação foram realizadas com centenas de jovens das mais diversas regiões do país, possibilitando a formação, em 2011, de uma equipe de 14 correspondentes-bolsistas, que recebem ajuda de custo do patrocinador para produzir 
pelo menos 14 conteúdos em áudio, texto e/ou vídeo, a cada mês. O RadioTube movimenta uma rede de 1,4 mil emissoras, na maioria comunitárias, enviando material via internet e, ocasionalmente, em mídia física. Em janeiro e maio de 2011, por exemplo, para contemplar 700 emissoras comunitárias, muitas delas sem acesso à rede mundial de computadores, enviou pelos Correios dois $C D s$ com 30 reportagens e 30 spots, cada, produzidos pela equipe do Criar Brasil.

Além de possibilitar a distribuição gratuita do material da Criar Brasil, via internet, o portal oferece a qualquer membro cadastrado a oportunidade de postar áudios, textos e vídeos, com licença Creative Commons (que permite copiar, distribuir, exibir e executar qualquer uma das publicações, além de usá-las como base para outras criações, desde que o autor original seja devidamente creditado), fazer o download de arquivos, enviá-los para outras mídias sociais e serviços de microblogging, como Twitter, Facebook e Orkut, fazer comentários e navegar por listas de destaques, distribuídos por temas que se revezam na capa. Estes destaques são agrupados em duas listas, uma de conteúdos eleitos pelos editores do Radiotube e outra, automatizada, com os arquivos mais visitados, mais comentados e últimas postagens.

O RadioTube conta com mais de 2,4 mil usuários cadastrados e 188 comunidades on-line. O site entrou no ar empregando o software de gerenciamento de conteúdo ICOX, desenvolvido de forma colaborativa pela Pontonet Consultoria em Internet, com apoio da FAPERJ e da Financiadora de Estudos e Projetos (Finep), através do Programa Rio Inovação, e coordenado pelo Instituto de Inteligência Coletiva (ICO). Em 2010, no entanto, a equipe do Criar Brasil, insatisfeita com problemas operacionais no uso do ICOX, optou pela construção de uma plataforma híbrida e pela adoção de outra ferramenta para compartilhamento de conteúdos em mídias sociais, a AddThis, proprietária, operada pela Clearsprings Technologies. No segundo semestre, a arquitetura do site foi alterada, com a implementação da AddThis sobre o ICOX, assim como a parte gráfica, redesenhada. Este processo ocorreu de modo conturbado, devido à escassez de recursos, o que acarretou grande rotatividade de mão-de-obra na equipe de programadores para web do portal. Com as mudanças, muitos áudios se perderam, obrigando os usuários a postá-los novamente, e títulos que continham acentos ou 
cedilhas acabaram desconfigurados, com estes caracteres sendo substituídos por símbolos ininteligíveis. Quando este artigo estava sendo fechado, a equipe de TI ainda trabalhava em questões consideradas problemáticas, como contadores de acessos, ajuste da ferramenta "incorporar", do $R S S$ e do vídeo hospedado no próprio servidor dedicado do portal.

Em julho de 2011, outro desafio: encerrou-se o contrato de patrocínio com a Petrobras, e a Criar Brasil buscava a renovação e outros apoios que permitissem a continuidade do projeto. Um sinal de que, mesmo com a adoção de ferramentas gratuitas e de softwares livres, projetos de comunicação alternativa esbarram em questões comuns aos empreendimentos comerciais - sobretudo, quanto à sustentabilidade e à necessidade de constantes investimentos tecnológicos e em pessoal especializado.

Relatório de avaliação do projeto, concluído em julho de 2011, revela um pouco dos hábitos dos usuários do portal. De um total de 71 consultados por meio de questionário on-line, $42 \%$ informaram veicular conteúdos postados em emissoras em ondas hertzianas, enquanto $40 \%$ disseram divulgar as publicações em sites, blogs ou fóruns na internet. Além disso, 31\% afirmaram usar conteúdos do RadioTube em atividades pedagógicas, o que mostra o potencial multiplicador da iniciativa.

Sessenta e cinco por cento dos que responderam ao questionário confirmaram a importância das mídias sociais, informando que fizeram uso delas para divulgar áudios postados. A maior parte das postagens em mídias sociais (38\%) era de notícias.

Os usuários consultados demonstraram especial interesse em radiojornalismo: reportagens são os tipos de conteúdos que mais os atraem, com $42 \%$ das respostas, seguidas de spots (18\%), documentários e entrevistas (ambos com 15\%). Embora o site ofereça também textos e vídeos, a maioria dos conteúdos acessados (58\%) é de áudios. A frequência de acesso ao portal é semanal para 38\% dos respondentes, e diária para outros $18 \%$. Do total de usuários ouvidos, $63 \%$ fazem ou já fizeram postagens.

As métricas revelam um site com tráfego de médio porte, mas em curva ascendente. Em junho de 2011, foram 596,5 mil pageviews, contra 361,9 mil no mês anterior. O total de downloads de arquivos postados no RadioTube atingiu 28.256 no 
mesmo período, contra 26.121 em maio. Já as postagens chegaram a 3.107, média superior a 100 por dia, ligeiramente acima das 3.010 registradas no mês anterior.

A partir de outubro de 2010, quando o envio dos arquivos via mídias sociais foi reconfigurado com a adoção da plataforma AddThis, até julho de 2011, ao todo 1.106 postagens foram compartilhadas, gerando, no entanto, apenas 27 cliques - um indício de que o prestígio do usuário que compartilha áudios e os usos das mídias sociais e microblogs pelo público-alvo são fatores decisivos para a circulação destes conteúdos. O Twitter foi a ferramenta mais utilizada, servindo ao compartilhamento de 503 arquivos. Em seguida, vêm os sites de relacionamentos Facebook, com 291, e Orkut, com 142, envio por email, com 99, e o motor de buscas Google, com 43.

As métricas da AddThis identificam oito usuários como influentes, responsáveis pela grande maioria dos compartilhamentos. Outros 403 são apontados como compartilhadores, ou seja, repassam regularmente os arquivos distribuídos pelos influentes para suas próprias redes sociais.

Os números podem parecer pouco expressivos, mas ganham novos contornos se considerarmos que a maioria dos usuários ( $82 \%$ dos que responderam ao questionário) representa instituições ou emissoras comunitárias, que fazem uso dos áudios postados em sua programação veiculada em ondas hertzianas. Ou seja, um punhado de downloads de um arquivo podem representar uma audiência de milhares de pessoas, nas mais diversas regiões do país.

A análise, aqui apresentada, desconsidera a circulação dos arquivos compartilhados pelas diversas redes de amigos e seguidores dos usuários no Twitter, no Facebook e no Orkut. A apuração do grau de difusão em cada um destes serviços exigiria o emprego de ferramentas, como softwares específicos, para aferir quantas vezes cada arquivo foi compartilhado a partir do compartilhamento inicial. Considerando-se a abrangência da amostra selecionada, optou-se por utilizar apenas os dados da plataforma AddThis, que oferece métricas gratuitas, embora limitadas. 


\section{Considerações finais}

Serviços de rádio social como o RadioTube oferecem à radiodifusão comunitária e a outros pequenos radiodifusores alternativas em termos de fontes de informação, ferramentas de distribuição e estratégias de circulação, num momento em que proliferam novas tecnologias de informação e comunicação, mas escasseiam os investimentos em radiojornalismo - mesmo nos grandes grupos de comunicação, como Sistema Globo de Rádio (SGR) e Bandeirantes, que, embora protagonizem forte concorrência no segmento informativo, mantêm redações enxutas.

A convergência entre rádio e mídias sociais ainda aparece de modo incipiente na análise do compartilhamento dos conteúdos postados no RadioTube, mas deve se intensificar à medida que a internet ganhe capilaridade no país, ainda marcado por profundas desigualdades socioeconômicas. Mesmo assim, chama a atenção o fato de que um terço do material publicado no portal entre outubro de 2010 e julho de 2011 tenha sido compartilhado por meio de serviços de microblogging como Twitter e sites de relacionamento como Facebook e Orkut. O baixo retorno em número de cliques pode significar que a prática do compartilhamento tenha não apenas motivação de trazer novos ouvintes, mas sirva também a uma operação de prestígio, em que a presença de determinado radiodifusor na mídia social ajude a construir uma reputação que o credenciaria, num momento posterior, como fonte de informações gabaritada, digna de credibilidade.

Novas ferramentas deverão ser empregadas em futuras análises, para aferir até que ponto a circulação de conteúdos postados no portal atinge de fato um número expressivo de ouvintes de emissoras comunitárias e como estes áudios são, por sua vez, apropriados por estas audiências.

De todo modo, há indícios claros de que o rádio não apenas transborda para as mídias sociais, amplificando seu alcance, mas que o contrário também ocorre: pequenos radiodifusores - pessoas físicas, ONGs, movimentos sociais, empresas, universidades e etc. - chegam ao dial com conteúdos radiojornalísticos publicados antes na internet, invertendo a tradicional lógica do broadcasting. Estes podcasters, a despeito da pequena força que têm diante da indústria da radiodifusão sonora e da precária infra-estrutura 
tecnológica de que desfrutam, vêm competindo por atenção com a mídia de referência e, em certa medida, com o material veiculado pelas radioagências, muitas delas representantes de instituições públicas ou privadas que oferecem um radiojornalismo chapa-branca, desconectado dos interesses da população.

Nesse rádio social, expandido, novos serviços oferecem cada vez mais novos canais de distribuição e ferramentas que propiciam a circulação de conteúdos radiofônicos através de redes sociais e comunidades on-line, alimentadas por arquivos digitais de áudio em múltiplas mídias sociais e microblogs. Além disso, constitui, por si, espaço de fruição, consumo, apropriação destes conteúdos, concorrendo com as tradicionais formas de escuta radiofônica.

As relações assimétricas entre os integrantes destas redes, contudo, permanecem como uma barreira à entrada dos novos atores sociais na radiodifusão. Para quem não tem uma marca estabelecida, é preciso construir uma reputação para ganhar visibilidade nas redes e se fazer ouvir. Um desafio e tanto para as rádios comunitárias, que atuam em áreas de baixa renda e reduzida penetração da internet, enfrentando, ainda, a concorrência da mídia de referência e uma legislação restritiva que dificulta a captação de recursos para garantir sua sustentabilidade.

\section{Referências}

BUSTAMANTE, Enrique. (org.). Hacia un nuevo sistema mundial de comunicación: las industrias culturales en la era digital. Barcelona: Gedisa, 2003.

CEBRIÁN HERREROS, Mariano. La radio en Internet: de la ciberradio a las redes sociales y la radio móvil. Buenos Aires: La Crujía, 2008.

FERRARETTO, Luiz Artur; KISCHINHEVSKY, Marcelo. Rádio e convergência - Uma abordagem pela economia política da comunicação. Revista Famecos, vol. 17, n. 3, set.-dez. 2010.

HERSCHMANN, Micael; KISCHINHEVSKY, Marcelo. "A 'geração podcasting' e os novos usos do rádio na sociedade do espetáculo e do entretenimento". Revista Famecos, n. 37, pp. 101-106, dez. 2008.

KISCHINHEVSKY, Marcelo. Rádio social - Mapeando novas práticas interacionais sonoras. Anais... XX Encontro Anual da Compós. Porto Alegre: UFRGS, 2011. 
Estudos em Jornalismo e Mídia - Vol. $9 \mathrm{~N}^{\circ} \mathrm{I}$ - Janeiro a Junho de 2012 ISSNe 1984-6924

LOPEZ, Debora Cristina. Radiojornalismo hipermidiático: tendências e perspectivas do jornalismo de rádio all news brasileiro em um contexto de convergência tecnológica. Covilhã: UBI/LabCom Books, 2010 .

MACHADO, Elias. Sistemas de circulação no ciberjornalismo, in ECO-Pós, v. 11, n. 2, pp. 21-37. Rio de Janeiro: ago.-dez. 2008.

RECUERO, Raquel, ZAGO, Gabriela. A economia do retweet: Redes, difusão de informações e capital social no Twitter. Anais... XX Encontro Anual da Compós. Porto Alegre: UFRGS, 2011.

RECUERO, Raquel. Redes sociais na internet. Porto Alegre: Ed. Sulina, 2009.

ZAGO, Gabriela. Recirculação jornalística no twitter: filtro e comentário de notícias por interagentes como uma forma de potencialização da circulação. Dissertação de mestrado. Porto Alegre: Programa de Pós-Graduação em Comunicação e Informação, Fabico/UFRGS, 2011. 


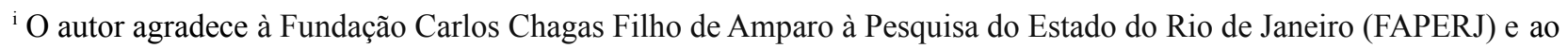
Conselho Nacional de Desenvolvimento Científico e Tecnológico $(\mathrm{CNPq})$ pelo apoio às pesquisas que possibilitaram a elaboração do presente artigo.

ii Ver http://www.teleco.com.br/pnad.asp (Última consulta: 21/6/2011).

${ }^{\text {iii } Q u a n d o ~ u m ~ u s u a ́ r i o ~ d o ~ s e r v i c ̧ o ~ r e e n c a m i n h a ~ u m a ~ m e n s a g e m ~ a ~ s u a ~ p r o ́ p r i a ~ r e d e ~ d e ~ s e g u i d o r e s, ~ a m p l i a n d o ~ s u a ~}$ circulação. A prática, também aportuguesada como retuitar ou abreviada para RT, não era prevista originalmente no serviço. Foi uma apropriação inesperada da ferramenta pelos usuários do Twitter, que conta com mais de 200 milhões de usuários cadastrados em todo o mundo e, em junho de 2011, recebia 460 mil novos cadastros por dia. As curtas mensagens - daí a noção de microblog -, conhecidas como tweets, chegam a 155 milhões diariamente. O mote é responder "o que está acontecendo agora?" e acumular "seguidores", que passam a acompanhar suas postagens. Endereço: http://twitter.com/. Última visita: 30/6/2011.

iv Informações institucionais disponíveis no endereço: http://www.radiotube.org.br. Última consulta: 30/6/2011. Outros dados que serão apresentados a seguir foram fornecidos em contatos eletrônicos e telefônicos pelo coordenador do projeto, André Lobão, a quem o autor deixa registrado um especial agradecimento. 